\title{
Faktor-faktor yang mempengaruhi kunjungan mahasiswa ke Perpustakaan Fakultas Kehutanan Univeritas Lancang Kuning
}

\author{
Eko Saputra Utama \\ Pustakawan Fakultas Kehutanan Universitas Lancang Kuning Pekanbaru Indonesia \\ Email: Ekosaputrautama@unilak.ac.id
}

\begin{abstract}
This study aims to determine the effect of library collections on student visits to the Faculty of Forestry Library of the University of Lancang Kuning. Type This research uses descriptive that is by collecting data obtained from respondents from the results of questionnaire answers and then the data tabulated. Sample determination was done by random sampling. While the data collection is done by survey method with questionnaire as collector of research data. The result of the research shows that the factors that influence the student visit to the library of Faculty of Forestry of the University of Lancang Kuning are Man Power (97.14\%), Library Collection (92.86\%), Building and Library Facility (91,43\%).
\end{abstract}

Keywords: Library, Effect of Visit

\begin{abstract}
ABSTRAK
Penelitian ini bertujuan mengetahui pengaruh koleksi perpustakaan terhadap kunjungan mahasiswa ke Perpustakaan Fakultas Kehutanan Universitas Lancang Kuning. Jenis penelitian ini menggunakan deskriptif yaitu dengan cara mengumpulkan data yang diperoleh dari responden dari hasil jawaban kuesioner dan kemudian data tersebut ditabulasikan. Penentuan sampel dilakukan secara Random sampling. Sedangkan pengumpulan data dilakukan dengan metode survei dengan kuesioner sebagai pengumpul data penelitian. Hasil penelitian menunjukkan bahwa faktor-faktor yang mempengaruhi kunjungan mahasiswa ke Perpustakaan Fakultas Kehutanan Universitas Lancang Kuning adalah Tenaga Pengelola (97,14 \%), Koleksi Perpustakaan (92,86 \%), Gedung dan Fasilitas Perpustakaan (91,43\%).
\end{abstract}

Kata Kunci: Perpustakaan, Pengaruh Kunjungan

\section{A. PENDAHULUAN}

Perpustakaan merupakan suatu wadah yang dapat digunakan oleh setiap kalangan atau tingkatan dimulai dari pendidikan sekolah dan perguruan tinggi. Perpustakaan ini didirikan agar dapat menunjang kegiatan belajar-mengajar yang digariskan dalam kurikulum untuk dapat berjalan dengan baik dan lancar. Adapun para pemakai perpustakaan perguruan tinggi adalah orang-orang yang berada didalam lingkungan perguruan tinggi, yaitu dosen, karyawan, dan mahasiswa.

Salah satu layanan yang diberikan adalah pengadaan bahan-bahan pustaka yang dapat menunjang kurikulum, dengan harapan para mahasiswa dapat mempertinggi daya serap dan penalaran proses pendidikan. Sementara para dosen dapat memperluas cakrawala dan pengetahuannya dalam kegiatan proses belajar mengajar. Demikian pula dengan para karyawan selain dosen, perpustakaan diharapkan dapat membantu mereka untuk lebih 
mengatahui dan menghayati tugasnya masing-masing. Namun, pada kenyataannya, perpustakaan perguruan tinggi tidaklah berjalan semulus yang diharapkan.

Pengunjung perpustakaan Fakultas Kehutanan Unilak sebanyak 6\% dari jumlah ratarata anggota berkunjung setiap harinya 15 orang dan jumlah pemustakanya sebanyak 250 orang iyang terdiri dari 13 orang dosen, 5 orang karyawan dan 232 orang mahasiswa. Perpustakaan perguruan tinggi ini dikelola sejak tahun 2015 akhir oleh pustakawan dan kepala perpustakaan. Layanan perpustakaan ini mulai berfungsi sejak 2015 akhir dilakukan pengolahan koleksi dan pada tahun 2016 awal sudah dilakukan layanan sirkulasi, layanan referensi maupun layanan fotocopy. Koleksi perpustakaan saat ini berjumlah 1797 judul dan 2675 eksemplar dengan berbagai macam koleksi seperti: buku, jurnal, majalah, prosiding, skripsi, laporan praktek ekosistem hutan, dan laporan praktek pengelolaan hutan lestari maupun laporan praktek kerja lapangan.

Beberapa hal yang sering menghambat fungsi perpustakaan perguruan tinggi ini adalah (1) Terbatasnya ruang perpustakaan di samping letaknya yang kurang strategis. Banyak iperpustakaan yang hanya menempati ruang sempit, tanpa memperhatikan kesehatan dan kenyamanan, (2) Keterbatasan bahan pustaka, baik dalam hal jumlah, variasi maupun kualitasnya, (3) Terbatasnya jumlah petugas perpustakaan (pustakawan), (4) Kurangnya promosi penggunaan perpustakaan menyebabkan tidak banyak mahasiswa yang mau memanfaatkan jasa layanan perpustakaan. Kurangnya ajakan untuk mengunjungi perpustakaan menjadikan mahasiswa merasa asing terhadap perpustakaan. Dengan demikian dapat dikatakan bahwa perpustakaan perguruan tinggi yang layak sebaiknya dilengkapi dengan koleksi-koleksi yang memadai, tenaga pengelola yang profesional, dan lain sebagainya.Berdasarakan uraian diatas maka penulis tertarik untuk melakukan penelitian tentang "Faktor-Faktor yang Mempengaruhi Kunjungan Mahasiswa ke Perpustakaan Fakultas Kehutanan Universitas Lancang Kuning”.

\section{B. TINJAUAN PUSTAKA}

Dalam bahasa Indonesia istilah "perpustakaan" dibentuk dari kata dasar pustaka ditambah awalan "per" dan akhiran "an". Menurut Moeljadi et al. (2016), Perpustakaan diartikan sebagai "kumpulan buku-buku (bahan bacaan). Dalam bahasa Inggris disebut "library" yang berarti perpustakaan. Dalam Menteri Hukum dan Hak Asasi Manusia Republik Indonesia (2014), Perpustakaan adalah institusi pengelola koleksi karya tulis, karya cetak, dan/atau karya rekam secara profesional dengan sistem yang baku guna memenuhi kebutuhan pendidikan, penelitian, pelestarian, informasi, dan rekreasi para pemustaka.

Menurut Sutarno NS (2006), Perpustakaan adalah suatu ruangan, bagian dari gedung/bangunan, atau gedung itu sendiri, yang berisi buku-buku koleksi, yang disusun dan diatur isedemikian rupa sehingga mudah dicari dan dipergunakan apabila sewaktu-waktu diperlukan untuk pembaca. Sedangkan menurut Larasati (2017), Perpustakaan adalah suatu unit kerja yang berupa tempat menyimpan koleksi bahan pustaka yang diatur secara sistematis dengan cara tertentu untuk digunakan secara berkesinambungan oleh pemakainya sebagai sumber informasi.

Dari beberapa pengertian di atas dapat ditarik suatu kesimpulan pengertian iperpustakaan secara umum adalah suatu unit kerja yang berupa tempat mengumpulkan, menyimpan dan memelihara koleksi pustaka baik buku-buku ataupun bacaan lainnya yang diatur, di organisasikan dan di administrasikan dengan cara tertentu untuk memberi kemudahan dan digunakan secara kontinyu oleh pemakainya sebagai informasi.

Dalam lampiran KEMENRISTEKDIKTI (2017) jenis-jenis perpustakaan, salah satunya Perpustakaan Perguruan Tinggi berfungsi sebagai sarana kegiatan belajar- 
mengajar, penelitian dan pengabdian masyarakat dalam pelaksanaan Tri Dharma Perguruan Tinggi. Sedangkan Dalam Menteri Hukum dan Hak Asasi Manusia Republik Indonesia (2014), Perpustakaan Perguruan Tinggi adalah perpustakaan yang merupakan bagian integral dari kegiatan pendidikan, penelitian dan pengabdian kepada masyarakat dan berfungsi sebagai pusat sumber belajar untuk mendukung tercapainya tujuan pendidikan yang berkedudukan di perguruan tinggi.

Dengan demikian dapatlah disimpulkan bahwa perpustakaan perguruan tinggi adalah suatu unit kerja dari sebuah lembaga perguruan tinggi yang berupa tempat menyimpan koleksi bahan pustaka penunjang proses pendidikan yang diatur secara sistematis untuk digunakan secara berkesinambungan sebagai sumber informasi untuk mengembangkan dan memperdalam pengetahuan, baik oleh pendidik maupun mereka yang dididik di perguruan tinggi tersebut.

Menurut M. Pawit Yusup dalam Berawi (2012), fungsi perpustakaan perguruan tinggi iadalah sebagai berikut:

a. Fungsi Edukasi

Dalam hal ini jelas, bahwa tugas pokok Perpustakaan Perguruan Tinggi ialah menunjang program Perguruan Tinggi yang salah satunya adalah bersifat edukasi. Sebagaimana kita ketahui bersama bahwa, cara belajar mahasiswa pada sebuah perguruan tinggi lebih bersifat serba aktif, hal ini terlihat dengan adanya kegiatan belajar terstruktur dan belajar mandiri sebagai tuntutan dari sistem SKS ( Sistem Kredit Semester ). Peranan dosen dalam hal ini bukan "mengajar" mahasiswa lagi , tetapi lebih tepat " membelajarkan" mahasiswa. Seorang mahasiswa lebih dituntut untuk membaca sebanyak mungkin bahan bacaan yang ada di perpustakaan, terutama bahan bacaan yang berhubungan dengan mata kuliah yang sedang di tempuh.

b. Fungsi Informasi

Peranan perpustakaan, disamping sebagai sarana pendidikan juga berfungsi sebagai pusat iinformasi. Diharapkan perpustakaan dapat memenuhi kebutuhan informasi sang pemakai (user). Terkadang memang tidak semua informasi yang dibutuhkan oleh pengguna dapat dipenuhi, karena memang tidak ada perpustakaan yang dapat memenuhi semua kebutuhan informasi pemakai. Untuk itu dibutuhkan peran pustakawan yang bisa memberikan arahan kemana sebaiknya mencari informasi yang dibutuhkan. Misalnya dengan menggunakan layanan rujukan dan media Internet.

c. Fungsi Riset ( Penelitian )

Salah satu fungsi dari Perpustakaan Perguruan Tinggi adalah mendukung pelaksanaan riset yang dilakukan oleh civitas akademika melalui penyediaan informasi dan sumbersumber informasi untuk keperluan penelitian pengguna. Informasi yang di peroleh melalui perpustakaan dapat mencegah terjadinya duplikasi penelitian. Kecuali penelitian yang akan dilakukan merupakan penelitian yang berkelanjutan. Oleh karena itu, melalui fungsi riset diharapkan karya-karya penelitian yang dilakukan oleh civitas akademik akan semakin berkembang.

d. Fungsi Rekreasi

Perpustakaan disamping berfungsi sebagai sarana pendidikan, juga berfungsi sebagai tempat rekreasi. Tentunya rekreasi yang dimaksud disini bukan berarti jalan-jalan untuk liburan, tetapi lebih berhubungan dengan ilmu pengetahuan. seperti dengan cara menyajikan koleksi yang menghibur pembaca misalnya bacaan humor, cerita perjalanan hidup seseorang, novel, dan membuat kreasi keterampilan. 
Adapun beberapa faktor yang mempengaruhi terhadap pemanfaatan perpustakaan perguruan tinggi adalah:

a. Minat baca

Faktor minat mahasiswa sangat menentukan terhadap pemanfaatan perpustakaan perguruan tinggi, karena adanya kesadaran pribadi mahasiswa sebagai pendorong jiwanya untuk memanfaatkan perpustakaan perguruan tinggi demi kelancaran studinya, Hal ini menunjukkan bahwa minat merupakan kecenderungan jiwa seseorang.

b. Tenaga Pengelola

Faktor ini sangat memegang peranan yang sangat menentukan berhasil tidaknya sebuah perpustakaan. Oleh karena itu untuk membuat perpustakaan bermanfaat sesuai dengan tugas, fungsi dan tujuannya. Maka para pengelola, penyelenggara bisa menyadari akan kepentingan dan kedudukan perpustakaan bagi pelajar, memahami keperluan mahasiswa dan kemudian menguasai liku-liku kegiatan dan teknik pekerjaan perpustakaan itu sendiri. Menurut Larasati (2017) Seorang pengelola perpustakaan tidak cukup hanya dibekali keahlian teknis dan pengetahuan yang memadai tentang ilmu keperpustakaan, melainkan harus memiliki kemampuan mental tertentu.

c. Koleksi Perpustakaan

Menurut Larasati (2017) bahwa fungsi perpustakaan adalah berusaha memberikan pelayanan kepada lembaga pendidikan agar kegiatan belajar mengajar yang digariskan dalam kurikulum dapat berjalan dengan lancar. Sesuai dengan maksud itulah maka perpustakaan harus dapat menyediakan segala keperluan peralatan yang menunjang pengajaran yang dilaksanakan di lembaga pendidikan baik berupa buku-buku pegangan, buku-buku pelengkap dan sebagainya maupun bahan-bahan pengajaran lainnya seperti alat peraga. Mengenai koleksi yang berupa buku, maka suatu perpustakaan paling tidak memerlukan buku-buku pegangan wajib mahasiswa, bukubuku pelengkap pelajaran mahasiswa dan buku-buku pegangan bagi dosen dalam mengajar.

d. Motivasi Dosen

Motivasi adalah kondisi psikologis yang mendorong untuk melakukan sesuatu. Menurut Mc. Donald dalam Sardiman (2014), motivasi adalah perubahan energi dalam diri seseorang yang ditandai dengan munculnya feeling dan didahului dengan tanggapan terhadap adanya tujuan. Ada dua jenis motivasi, yaitu:

1) Motivasi Intrinsik

Jenis motovasi ini timbul sebagai akibat dari dalam diri individu sendiri tanpa ada paksaan dorongan dari orang lain, tetapi atas kemampuan sendiri.

2) Motivasi Ekstrinsik

Jenis motivasi ini timbul sebagai akibat pengaruh dari luar individu, apakah karena adanya ajakan, suruhan atau paksaan dari orang lain sehingga dengan kondisi yang demikian akhirnya ia mau melakukan sesuatu atau belajar.

Sehubungan dengan pemanfaatan perpustakaan, maka motivasi dosen adalah merupakan salah satu faktor yang turut mempengaruhi, karena tanpa adanya motivasi yang diberikan oleh dosen untuk memanfaatkan perpustakaan dalam aktivitas belajarnya mahasiswa akan terpacu untuk meningkatkan aktivitas belajarnya. Conny Semiawan, et al. dalam Toha (2015), bahwa dosen hendaknya berperan sebagai pendorong, motivasi, agar motif-motif positif dibangkitkan dan atau ditingkatkan dari dalam diri anak. 
Motivasi yang diberikan oleh dosen di sini bukan hanya dalam membangkitkan gairah mahasiswa terhadap perpustakaan, namun juga bisa diberikan dengan penugasan yang mengharuskan mereka memanfaatkan bahan perpustakaan juga memberikan motivasi untuk gemar membaca.

e. Gedung dan Fasilitas Perpustakaan

Mengenai keadaan gedung perpustakaan ini yang harus diperhatikan adalah letak, jumlah ruangan dan tata ruangannya, yang perlu diperhatikan untuk mendirikan perpustakaan yaitu:

1) Letak

Perpustakaan berada di tengah-tengah tempat berlangsungnya kegiatan lembaga pendidikan, sehingga mudah dicapai dari segala arah.

2) Konstruksi/ keadaan gedung

Mampu menahan berat perabot dan isinya, tahan api dan tahan bakar, cukup banyak celah untuk memungkinkan memberi penerangan secara alamiah dan tanpa banyak tiang serta penyekat.

3) Pengaturan ruangan

Tergantung dari luas serta bentuk ruangan, dan demi kemudahan pelayanan, tetapi haruslah diperhatikan juga segi-segi arsistik, kenyamanan ventilasi, kesegaran ruangan dan keasriannya.

Selain gedung, fasilitas perpustakaan merupakan hal yang penting, yang idimaksudkan adalah segala perkakas yang digunakan dalam penyelenggaraan perpustakaan selain buku-buku dan bahan pustaka. Perlengkapan atau fasilitas ini meliputi rak buku, rak surat kabar, rak majalah, kabinet gambar, meja sirkulasi, lemari atau kabinet katalog, papan display, papan pengumuman, meja baca dan perlengkapan lainnya yang digunakan secara tidak langsung.

\section{METODE PENELITIAN}

Penelitian ini berlokasi di Perpustakaan Fakultas Kehutanan Universitas Lancang Kuning yang dilakukan selama 3 bulan mulai Oktober sampai Desember 2019. Penelitian ini menggunakan deskriptif yaitu dengan cara mengumpulkan data yang diperoleh dari responden dari hasil jawaban kuesioner dan kemudian data tersebut ditabulasikan.

Pengumpulan data dilakukan dengan menggunakan kuesioner. Kuesioner disebarkan kepada mahasiswa yang berkunjung ke perpustakaan. Pengisian kuesioner dilakukan oleh mahasiswa sejumlah 70 orang mahasiswa dengan menggunakan metode random sampling. Faktor yang mempengaruhi mahasiswa berkunjung ke perpustakaan yang dilakukan yakni: Minat Baca, Tenaga Pengelola, koleksi perpustakaan, motivasi dosen, Gedung dan Fasilitas Perpustakaan yang dibuat dalam bentuk kuisioner. Sistem penilaian menggunakan skala Likert dengan 3 alternatif pilihan jawaban yang bergerak dari angka 1 (Tidak), 2 (Ragu) dan 3 (Ya).

\section{HASIL DAN PEMBAHASAN}

Adapun hasil penelitian dari data-data yang diperoleh dari responden melalui kuesioner yang telah disebarkan yaitu sebanyak 70 kuesioner terhadap 70 responden terpilih antara lain: 
Tabel 1. Tanggapan Responden Atas Pernyataan Bahwa Koleksi Buku Perpustakaan Fakultas Kehutanan Universitas Lancang Kuning Sudah Memadai

\begin{tabular}{|c|l|c|c|}
\hline No & Jawaban & Jumlah & Persentase (\%) \\
\hline 1 & Ya & 18 & $25,71 \%$ \\
\hline 2 & Ragu-Ragu & 25 & $35,72 \%$ \\
\hline 3 & Tidak & 27 & $38,57 \%$ \\
\hline \multicolumn{2}{|c|}{ Jumlah } & 70 & $100 \%$ \\
\hline
\end{tabular}

Berdasarkan tabel diatas dapat disimpulkan bahwa tanggapan responden terhadap pernyataan koleksi buku perpustakaan Fakultas Kehutanan Universitas Lancang Kuning sudah memadai adalah $25,71 \%$ menjawab ya, 35,72 \% menjawab ragu-ragu dan 38,57\% menjawab tidak.

Tabel 2. Tanggapan Responden Atas Pernyataan Bahwa Koleksi Perpustakaan Berpengaruh Terhadap Minat Baca Mahasiswa di Perpustakaan Fakultas Kehutanan Universitas Lancang Kuning

\begin{tabular}{|c|l|c|c|}
\hline No & Jawaban & Jumlah & Persentase (\%) \\
\hline 1 & Ya & 63 & $90,00 \%$ \\
\hline 2 & Ragu-Ragu & 6 & $8,57 \%$ \\
\hline 3 & Tidak & 1 & $1,43 \%$ \\
\hline \multicolumn{2}{|c|}{ Jumlah } & 70 & $100 \%$ \\
\hline
\end{tabular}

Berdasarkan tabel diatas dapat disimpulkan bahwa tanggapan responden terhadap pernyataan koleksi perpustakaan berpengaruh terhadap minat baca mahasiswa di Perpustakaan Fakultas Kehutanan Universitas Lancang Kuning adalah 90,00 \% menjawab ya, 8,57 \% menjawab ragu-ragu dan $1,43 \%$ menjawab tidak.

Tabel 3. Tanggapan Responden Atas Pernyataan Koleksi Buku Perpustakaan Dapat Membantu Proses Belajar Mengajar

\begin{tabular}{|c|l|c|c|}
\hline No & Jawaban & Jumlah & Persentase (\%) \\
\hline 1 & Ya & 65 & $92,86 \%$ \\
\hline 2 & Ragu-Ragu & 5 & $7,14 \%$ \\
\hline 3 & Tidak & 0 & $0 \%$ \\
\hline \multicolumn{2}{|c|}{ Jumlah } & 70 & $100 \%$ \\
\hline
\end{tabular}

Berdasarkan tabel diatas dapat disimpulkan bahwa tanggapan responden koleksi buku perpustakaan dapat membantu proses belajar - mengajar adalah 92,86\% menjawab ya, 7,14\% menjawab ragu-ragu dan $0 \%$ menjawab tidak.

Tabel 4. Tanggapan Responden Atas Pernyataan Ruang Baca Perpustakaan Sudah Nyaman

\begin{tabular}{|c|l|c|c|}
\hline No & \multicolumn{1}{|c|}{ Jawaban } & Jumlah & Persentase (\%) \\
\hline 1 & Ya & 62 & $88,57 \%$ \\
\hline 2 & Ragu-Ragu & 6 & $8,57 \%$ \\
\hline 3 & Tidak & 2 & $2,86 \%$ \\
\hline
\end{tabular}




\begin{tabular}{|c|c|c|}
\hline Jumlah & 70 & $100 \%$ \\
\hline
\end{tabular}

Berdasarkan tabel diatas dapat disimpulkan bahwa tanggapan responden terhadap pernyataan ruang baca perpustakaan sudah nyaman adalah 88,57 \% menjawab ya, 8,57 \% menjawab ragu-ragu dan $2,86 \%$ menjawab tidak.

Tabel 5. Tanggapan Responden Atas Pernyataan Tenaga Pengelola Ataupun Pustakawan Cukup Ramah Dalam Melayani Pemustaka/Pengguna

\begin{tabular}{|c|l|c|c|}
\hline No & Jawaban & Jumlah & Persentase (\%) \\
\hline 1 & Ya & 68 & $97,14 \%$ \\
\hline 2 & Ragu-Ragu & 0 & $0 \%$ \\
\hline 3 & Tidak & 2 & $2,86 \%$ \\
\hline \multicolumn{2}{|c|}{ Jumlah } & 70 & $100 \%$ \\
\hline
\end{tabular}

Berdasarkan tabel diatas dapat disimpulkan bahwa tanggapan responden terhadap pernyataan tenaga pengelola ataupun pustakawan cukup ramah dalam melayani pemustaka / pengguna adalah 97,14\% menjawab ya, \% menjawab ragu-ragu dan 2,86 \% menjawab tidak.

Tabel 6. Tanggapan Responden Atas Pernyataan Letak Perpustakaan Cukup Strategis Untuk Dikunjungi

\begin{tabular}{|c|l|c|c|}
\hline No & Jawaban & Jumlah & Persentase (\%) \\
\hline 1 & Ya & 54 & $77,14 \%$ \\
\hline 2 & Ragu-Ragu & 8 & $11,43 \%$ \\
\hline 3 & Tidak & 8 & $11,43 \%$ \\
\hline \multicolumn{2}{|c|}{ Jumlah } & 70 & $100 \%$ \\
\hline
\end{tabular}

Berdasarkan tabel diatas dapat disimpulkan bahwa tanggapan responden terhadap pernyataan letak perpustakaan cukup strategis untuk dikunjungi adalah 77,14\% menjawab ya, $11,43 \%$ menjawab ragu-ragu dan $11,43 \%$ menjawab tidak.

Tabel 7. Tanggapan Responden Atas Pernyataan Meja Baca di Perpustakaan Sudah Layak Digunakan Oleh Pemustaka

\begin{tabular}{|c|l|c|c|}
\hline No & \multicolumn{1}{|c|}{ Jawaban } & Jumlah & Persentase (\%) \\
\hline 1 & Ya & 54 & $77,14 \%$ \\
\hline 2 & Ragu-Ragu & 9 & $12,86 \%$ \\
\hline 3 & Tidak & 7 & $10,00 \%$ \\
\hline \multicolumn{2}{|c|}{ Jumlah } & 70 & $100 \%$ \\
\hline
\end{tabular}

Berdasarkan tabel diatas dapat disimpulkan bahwa tanggapan responden terhadap pernyataan meja baca diperpustakaan sudah layak digunakan oleh pemustaka adalah 77,14 $\%$ menjawab ya, $12,86 \%$ menjawab ragu-ragu dan $10,00 \%$ menjawab tidak. 
Tabel 8. Tanggapan Responden Atas Pernyataan Perpustakaan Sudah Memperhatikan Kesehatan Pengunjungan Di Perpustakaan

\begin{tabular}{|c|l|c|c|}
\hline No & Jawaban & Jumlah & Persentase (\%) \\
\hline 1 & Ya & 28 & $40,00 \%$ \\
\hline 2 & Ragu-Ragu & 27 & $38,57 \%$ \\
\hline 3 & Tidak & 15 & $21,43 \%$ \\
\hline \multicolumn{2}{|c|}{ Jumlah } & 70 & $100 \%$ \\
\hline
\end{tabular}

Berdasarkan tabel diatas dapat disimpulkan bahwa tanggapan responden terhadap pernyataan perpustakaan sudah memperhatikan kesehatan kunjungan di Perpustakaan adalah $40,00 \%$ menjawab ya, 38,57 \% menjawab ragu-ragu dan $21,43 \%$ menjawab tidak.

Tabel 9. Tanggapan Responden Atas Pernyataan Dosen Memberikan Motivasi Untuk Menggunjungi Perpustakaan Yang Disediakan

\begin{tabular}{|c|l|c|c|}
\hline No & \multicolumn{1}{|c|}{ Jawaban } & Jumlah & Persentase (\%) \\
\hline 1 & Ya & 38 & $54,29 \%$ \\
\hline 2 & Ragu-Ragu & 14 & $20,00 \%$ \\
\hline 3 & Tidak & 18 & $25,71 \%$ \\
\hline \multicolumn{2}{|c|}{ Jumlah } & 70 & $100 \%$ \\
\hline
\end{tabular}

Berdasarkan tabel diatas dapat disimpulkan bahwa tanggapan responden terhadap pernyataan dosen memberikan motivasi untuk menggunjungi perpustakaan yang disediakan adalah 54,29 \% menjawab ya, 20,00\% menjawab ragu-ragu dan $25,71 \%$ menjawab tidak.

Tabel 10. Tanggapan Responden Atas Pernyataan Perpustakaan Memberikan Pengaturan Ruangan

\begin{tabular}{|c|l|c|c|}
\hline No & \multicolumn{1}{|c|}{ Jawaban } & Jumlah & $\begin{array}{c}\text { Persentase } \\
(\%)\end{array}$ \\
\hline 1 & Ya & 64 & $91,43 \%$ \\
\hline 2 & Ragu-Ragu & 5 & $7,14 \%$ \\
\hline 3 & Tidak & 1 & $1,43 \%$ \\
\hline \multicolumn{2}{|c|}{ Jumlah } & 70 & $100 \%$ \\
\hline
\end{tabular}

Berdasarkan tabel diatas dapat disimpulkan bahwa tanggapan responden terhadap pernyataan perpustakaan memberikan pengaturan ruangan seperti rak buku, rak surat kabar, rak majalah, kabinet gambar, meja sirkulasi, lemari atau kabinet katalog, papan display, papan pengumuman, meja baca dan perlengkapan lainnya adalah 91,43\% menjawab ya, $7,14 \%$ menjawab ragu-ragu dan $1,43 \%$ manjawab tidak.

Berdasarkan tabel 1 sampai 10 dapat disimpulkan bahwa tenaga pengelola perpustakaan diperoleh data dengan 97, $14 \%$ responden memiliki pengaruh terhadap kunjungan perpustakaan dan koleksi buku diperpustakaan masih perlu ditambah lagi baik dalam hal jumlah maupun variasinya karena dari hasil penelitian ini diperoleh data bahwa $90,00 \%$ dari responden menyatakan setuju bahwa koleksi buku diperpustakaan sangat berpengaruh terhadap minat baca mahasiswa dan 92,86 \% setuju bahwa koleksi perpustakaan dapat membantu mahasiswa dalam proses belajar di Fakultas Kehutanan Universitas Lancang Kuning. Tabel diatas juga menyimpulkan bahwa dosen perlu 
memberikan motivasi untuk mengunjungi perpustakaan yang disediakan dan koleksi buku perpustakaan Fakultas Kehutanan Universitas Lancang Kuning tidak memadai.

\section{E. KESIMPULAN}

\section{Kesimpulan}

Perpustakaan Fakultas Kehutanan Universitas Lancang Kuning adalah salah satu wadah untuk menyalurkan minat baca seseorang terutama mahasiswa, untuk itu maka perpustakaan yang baik seharusnya mempunyai banyak bahan pustaka yang dapat membantu mahasiswa dalam menyalurkan minat baca dan membantu mereka dalam proses belajar. Perpustakaan hendaknya juga memperhatikan kenyamanan para pengunjungnya karena sesuai dengan fungsi perpustakaan yang tidak hanya sebagai sarana pendidikan tetapi juga sebagai tempat rekreasi bagi mahasiswa dalam menghilangkan kejenuhan dari suasana belajar yang ada. Sebagai salah satu faktor yang mempengaruhi kunjungan mahasiswa ke perpustakaan, koleksi buku diperpustakaan hendaknya sesuai dengan kurikulum yang berlaku di lembaga pendidikan tersebut agar dapat membantu mahasiswa dalam proses belajarnya.

\section{Saran}

Perpustakaan Fakultas Kehutanan Universitas Lancang Kuning harus memiliki jumlah buku yang cukup memadai baik dalam jumlah maupun variasinya sesuai dengan kebutuhan mahasiswanya. Perpustakaan Fakultas Kehutanan Universitas Lancang Kuning seharusnya juga memperhatikan memperhatikan kesehatan pengunjungan di perpustakaan, sehingga kenyamanan pengunjung juga merupakan sesuatu hal yang penting dan harus mendapatkan perhatian. Ruangan yang sejuk, tata ruang yang baik serta alunan musik santai akan membuat mahasiswa sebagai pengunjung perpustakaan merasa nyaman dan mampu menghabiskan banyak waktu di perpustakaan.

\section{DAFTAR PUSTAKA}

Berawi, Imran. 2012. "Mengenal Lebih Dekat Perpustakaan Perguruan Tinggi." Jurnal Iqra' 6 (1): 49-62. http://repository.uinsu.ac.id/690/1/iqra' 2012 vol.06 no. 01 - Copy (7).pdf.

KEMENRISTEKDIKTI. 2017. "Keputusan Menteri Riset, Teknologi, Dan Pendidikan Tinggi Republik Indonesia Nomor 2 Tahun 2016." No 257/M/Kpt/2017. ihttps://doi.org/10.1007/s11606-010-1529-0.

Larasati. 2017. Yoykarta: e-Journal Universitas Atma Jaya Yogyakarta. http://ejournal.uajy.ac.id/643/3/2TA12721.pdf.

Menteri Hukum dan Hak Asasi Manusia Republik Indonesia. 2014. "Peraturan Pemerintah Republik iIndonesia Nomor 24 Tahun 2014 Tentang Pelaksanaan Undang-Undang Nomor 43 Tahun 2007 Tentang Perpustakaan." Lembaran Negara Republik Indonesia Tahun 2014 Nomor 76.

Moeljadi, David, Randy Sugianto, Jaya Satrio Hendrick, and Kenny Hartono. 201AD. "Kamus Besar Bahasa Indinesia Edisi Ke Lima."

Sardiman, iAm. 2014. Interaksi Dan Motivasi Belajar Mengajar. Interaksi \& Motivasi Belajar Mengajar.

Sutarno NS. 2006. “Perpustakaan Dan Masyarakat.” In Perpustakaan Dan Masyarakat.

Toha, Muhamad. 2015. "Upaya Pengelola Perpustakaan Dalam Meningkatkan Miat Baca Siswa Pada Mata Pelajaran Pendidikan Agama Islam (Studi Multi Situs Di MTs Negeri Tulungagung Dan MTs As-Syafi'iyah Gondang)." IAIANTulungAgung. 